\title{
Numerical Simulation and Experimental Research on Coal Ash Collecting and Grading System
}

\author{
Yuanhua Xie, Xianjin Li, Liwei Wang, Hong Yu, Bing Bai, Zhizhou Xu, and Tong Zhu
}

School of Mechanical Engineering and Automation, Northeastern University, 3-11 Wenhua Road, Heping District, Shenyang 110004, China

Correspondence should be addressed to Tong Zhu; tongzhu@mail.neu.edu.cn

Received 14 June 2014; Accepted 14 July 2014; Published 6 August 2014

Academic Editor: Jun Liu

Copyright (C) 2014 Yuanhua Xie et al. This is an open access article distributed under the Creative Commons Attribution License, which permits unrestricted use, distribution, and reproduction in any medium, provided the original work is properly cited.

\begin{abstract}
The grading separation of coal ash can not only increase its economic value but also decrease its pollution to environment. Based on the jet-attracting flow technology and the gas-solid two-phase flow theory, the force and motion of coal ash particles in airflow were studied firstly. Focused on single coal ash particle, Matlab software was used to simulate the force conditions and separation parameters of various diameter coal ash particles in airflow. Fluent software was used to simulate the nozzle fluidization domain shape and to determine optimal jet flux. According to the theoretical results, a coal ash collecting and grading system was developed. Using the separation efficiency as the evaluation index, the optimal experiment parameters of jet flux, attracting flux, and separation time were obtained. At last, the calculated results and experimental results of coal ash particles median diameter from the first grading separation exit under various attracting fluxes were compared. The reasons that could cause the errors were discussed. This study has significant practical meaning and application value on coal ash collecting and grading separation.
\end{abstract}

\section{Introduction}

Coal ash is the solid waste of burning coal. Except for dust air pollution, coal ash can result in groundwater pollution and soil pollution due to its compositions of trace amounts of heavy metals and tiny amounts of radioactive substances. Coal ash can also cause geological disasters [1]. However, coal ash contains many kinds of useful substances, such as glass microbead, high-aluminum powder, and carbon powder. Collecting and separating these substances effectively can greatly increase the economic value of coal ash, which can turn the waste into treasure and has more important meaning on environment protection [2].

At present, the coal ash grading separation methods mainly include sieving, airflow classification, froth flotation, electrostatic separation, and magnetic separation $[3,4]$. For the separation of high fineness coal ash, the airflow classification is often used $[5,6]$. The basic principle of airflow classification is to separate the lighter material out of the separation device upward or to take the lighter material to relatively distant place along the horizontal direction by airflow. The heavier material will settle because the airflow cannot bear its weight. The separated lighter material can be further separated by cyclone separator [7]. Some problems in the present airflow classification process are showed as follows [4]. The high fineness requirement to coal ash increases the design difficulty of coal ash grading device. The performance and efficiency of separation device are severely affected by the seal and abrasion. How can we combine the theory analysis and experimental test? How can we solve the contradiction between high work capacity and high grading fineness? How can we solve low grading efficiency and low grading accuracy under high work capacity?

Based on the jet-attracting flow technology [8-11] and gas-solid two-phase flow theory [12-14], a new coal ash collecting and grading device was developed in this study. The new device could achieve the grading separation of coal ash while collecting and transporting. The force and motion of coal ash particles in airflow were studied in theory. Then the force and separation condition of various diameter coal ash particles in airflow were simulated by Matlab software. The Fluent software was also used to simulate the shape of nozzle fluidization domain and to determine the optimal jet flux. Finally, the coal ash collecting and grading device 
was used for the relevant experiments to study the relations between the separation efficiency and jet flux, attracting flux or separation time. The calculated and experimental values of coal ash particle median diameter in the first grading separation exit under different attracting flux were compared. The reasons causing the errors were also discussed.

\section{Analysis of Force and Motion of Coal Ash Particles in Airflow}

Single particle dynamics (SPD) is the simplest method in studying the suspension two-phase flow. In SPD method, the airflow field is regarded as known field, without considering the particle fluctuation and the influence of particles on fluid flow, but only considering the force and motion of a single particle that is uncorrelated with other particles in flow field [15].

2.1. Analysis of Force of Coal Ash Particles in Airflow. The study of particle force is the core problem of particle motion in gas-solid two-phase flow [16]. The exchange of momentum and energy between fluid and solid particles existed when coal ash particles move in fluid. The two phases will interact and interplay with each other. The coupling of the gas phase and the solid phase was achieved by the interacting forces between them.

The forces on coal ash particles could be classified into 4 categories based on their different action modes during the motion in fluid [17]: (1) the forces that are uncorrelated with interaction between the particles and fluid, such as gravity, buoyancy, and pressure gradient force, (2) the forces that are depending on the relative motion between the particles and fluid and are collinear with the relative velocity direction, such as traction resistance, additional mass force, and Basset force, (3) the forces that are correlated with the relative motion between the particles and fluid but are perpendicular to the relative velocity direction, such as Magnus lift force and Saffman lift force, and (4) the collision resistance between particles.

In the separation process of the coal ash collecting and grading device designed in this study, the main direction of particles movement was vertical. So only the vertical forces were considered in the force analysis. And the particle motions were regarded as the simple one-dimensional vertical movement. Besides, considering that the density of coal ash particle was greater than that of the airflow during the separation process, some forces were ignored. The forces mentioned below were the concerned ones in the forces analysis process.

2.1.1. Gravity. The gravity of coal ash particles in airflow could be obtained from the following equation:

$$
F_{g}=m_{c} g=\rho_{c} V_{c} g=\frac{\pi}{6} d_{c}^{3} \rho_{c} g .
$$

In this equation, $F_{g}$ was gravity $(\mathrm{N}) ; m_{c}$ was the mass of coal ash particles $(\mathrm{kg}) ; g$ was gravitational acceleration $\left(9.8 \mathrm{~m} / \mathrm{s}^{2}\right)$; $\rho_{c}$ was the density of coal ash particles $\left(\mathrm{kg} / \mathrm{m}^{3}\right)$ and usually was $1900 \sim 2900 \mathrm{~kg} / \mathrm{m}^{3}$ [14]; $V_{c}$ was the volume of coal ash particles $\left(\mathrm{m}^{3}\right) ; d_{c}$ was the equivalent volume diameter of coal ash particles $(\mathrm{m})$.

2.1.2. Buoyancy. The buoyancy of coal ash particles in airflow was shown as follows:

$$
F_{f}=\rho_{g} V_{c} g=\frac{\pi}{6} d_{c}^{3} \rho_{g} g .
$$

In this equation, $F_{f}$ was buoyancy $(\mathrm{N})$; $\rho_{g}$ was the density of airflow $\left(\mathrm{kg} / \mathrm{m}^{3}\right)$.

2.1.3. Pressure Gradient Force. For a single particle (or suspension system with very low concentration), the fluid flow was not affected by the existing small particles. For the fluid phase, the following equation existed:

$$
\rho_{g} \frac{d v_{g}}{d t}=-\nabla p
$$

In this equation, $v_{g}$ was the airflow velocity $(\mathrm{m} / \mathrm{s}) ; t$ was time $(\mathrm{s}) ;-\nabla p$ was the pressure gradient $(\mathrm{Pa} / \mathrm{m})$.

Then the pressure gradient force could be expressed with

$$
F_{p}=\rho_{g} V_{c} \frac{d v_{g}}{d t}=\frac{1}{6} \pi d_{c}^{3} \rho_{g} \frac{d v_{g}}{d t} .
$$

In this equation, $F_{p}$ was the pressure gradient force $(\mathrm{N})$.

2.1.4. Traction Resistance. In gas-solid two-phase fluid, the movement of particles would be hindered by the impact from airflow. The impact from airflow was called traction resistance. The traction resistance of coal ash particles during its upward and settlement process in airflow could be expressed by (5) as follows:

$$
F_{d}=\frac{1}{2} \rho_{g}\left(v_{g}-v_{c}\right)^{2} C_{D} A=\frac{1}{2} \rho_{g}\left(v_{g}-v_{c}\right)^{2} C_{D} \frac{\pi d_{c}^{2}}{4} .
$$

In this equation, $F_{d}$ was the traction resistance $(\mathrm{N}) ; v_{c}$ was the coal ash particles velocity $(\mathrm{m} / \mathrm{s}) ; C_{D}$ was the traction coefficient; $A$ was the windward area of coal ash particle equivalent volume $\left(\mathrm{m}^{2}\right)$.

Traction coefficient $C_{D}$ had very close relation with particle Reynolds number $\operatorname{Re}_{p}$ and other factors as particle shape, roughness of particle surface, turbulivity of fluid, rotation of particle, and so on. When Reynolds number $\mathrm{Re}_{p}$ was slightly higher $\left(0 \leq \operatorname{Re} \leq 2 \times 10^{5}\right)$, the empirical formula from experiment data was very useful and the error was about $\pm 10 \% . C_{D}$ could be expressed by

$$
C_{D}=\frac{24}{\operatorname{Re}_{p}}+\frac{6}{1+\sqrt{\operatorname{Re}_{p}}}+0.4 .
$$

In this equation, $\operatorname{Re}_{p}$ was particle Reynolds number. 
Because $\operatorname{Re}_{p}=\left(v_{g}-v_{c}\right) d_{c} / \mu$ and gas viscosity $\mu=1.79 \times$ $10^{-5} \mathrm{~Pa} \cdot \mathrm{s}$ at room temperature $\left(20^{\circ} \mathrm{C}\right),(6)$ can be converted to

$$
\begin{aligned}
C_{D}= & \frac{4.296 \times 10^{-4}}{\left[d_{c}\left(v_{g}-v_{c}\right)\right]} \\
& +\frac{6}{\left[1+\sqrt{\left(d_{c}\left(v_{g}-v_{c}\right)\right) /\left(1.79 \times 10^{-5}\right)}\right]}+0.4 .
\end{aligned}
$$

In this equation, $v_{c}$ was the particle velocity $(\mathrm{m} / \mathrm{s})$.

2.1.5. False Mass Force. When a certain mass of coal ash particles did the accelerated movement in airflow field, the air around it would be accelerated together as well. This was equivalent to the fact that the particles had a false mass force. For the spherical particle with accelerated movement, the false mass force was equaled to the product of half mass of displacing air by particle and air acceleration relative to particle. The false mass force of single coal ash particle was [18]

$$
F_{v m}=\frac{1}{2} \rho_{g} V_{c}\left(\frac{d v_{g}}{d t}-\frac{d v_{c}}{d t}\right)=\frac{1}{12} \pi d_{c}^{3} \rho_{g}\left(\frac{d v_{g}}{d t}-\frac{d v_{c}}{d t}\right) .
$$

In this equation, $F_{v m}$ was the false mass force $(\mathrm{N})$.

2.2. Analysis of Motion of Coal Ash Particles in Airflow. Based on the simplified force analysis, the motion state of coal ash particles in airflow could be judged by its settling velocity, and the particle kinetic equation could be used to analyze the motion process of coal ash particles in airflow. For the gassolid two-phase flow, particle kinetics could be considered as the basic phenomena of actual gas-solid two-phase flow. The particle motion equation could be established according to the force balance of particle. The track of particle could be obtained by solving particle motion differential equation [19]:

$$
F=F_{g}+F_{f}+F_{p}+F_{d}+F_{v m} .
$$

Bringing (1), (2), (4), (5), and (8) to (9), (10) could be obtained:

$$
\begin{aligned}
\frac{\pi}{6} d_{c}^{3} \rho_{c} \frac{d v_{c}}{d t}= & -\frac{\pi}{6} d_{c}^{3} \rho_{c} g+\frac{\pi}{6} d_{c}^{3} \rho_{g} g \\
& +\frac{\pi}{6} d_{c}^{3} \rho_{g} \frac{d v_{g}}{d t}+\frac{\pi}{8} d_{c}^{2} \rho_{g} C_{D}\left(v_{g}-v_{c}\right)^{2} \\
& -\frac{1}{12} \pi d_{c}^{3} \rho_{g}\left(\frac{d v_{c}}{d t}-\frac{d v_{g}}{d t}\right)
\end{aligned}
$$

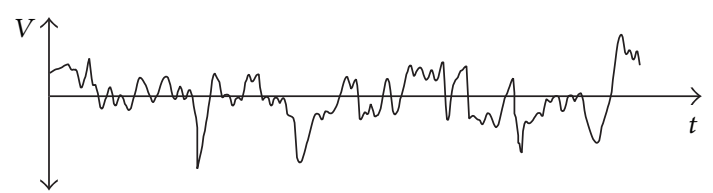

FIGURE 1: Velocity changes in turbulence.

After final transformation, it could be expressed as follows:

$$
\begin{aligned}
& \frac{d v_{c}}{d t}=\frac{2}{2 \rho_{c}+\rho_{g}} \\
& \times\left\{-\rho_{c} g+\rho_{g} g+\frac{3}{4} \frac{\rho_{g}}{d_{c}}\right. \\
& \times\left[\frac{4.296 \times 10^{-4}}{d_{c}\left(v_{g}-v_{c}\right)}\right. \\
& \left.+\frac{6}{1+\sqrt{d_{c}\left(v_{g}-v_{c}\right) /\left(1.79 \times 10^{-5}\right)}}+0.4\right] \\
& \left.\times\left(v_{g}-v_{c}\right)^{2}+\frac{3}{2} \rho_{g} \frac{\partial v_{g}}{\partial t}\right\} \text {. }
\end{aligned}
$$

However, the representation of particle motion in turbulent gas-solid flow by this mathematical model was still insufficient. The changes of turbulent flow velocity were shown in Figure 1.

The airflow velocity fluctuations caused by turbulent flow could also cause pulsation of granular materials. So, the fluctuations of turbulent flow had a very important influence on the separation of coal ash. Due to turbulence's complexity, irregularity, and occasionality, time function of the pulsating component could only be studied by statistical methods [20]. The effects of turbulent pulsation frequency on the following features of material in the fluid were also very complicated $[21,22]$. In this study, turbulent fluctuation waveform was simplified as sinusoidal and the air separation theory established by C. Rheet Jackson and Richard Ian Stessel could be extended to turbulence.

The simplified turbulent pulsating airflow velocity was expressed as:

$$
v_{g}=v_{g p}+v_{g m} \sin (\omega t) .
$$

In this equation, $v_{g p}$ was the average airflow velocity $(\mathrm{m} / \mathrm{s})$; $v_{g m}$ was the pulsating amplitude of airflow velocity $(\mathrm{m} / \mathrm{s}) ; \omega$ was the turbulent fluctuation frequency $(\mathrm{rad} / \mathrm{s})$.

Combining (11) and (12), more accurate mathematical model of coal ash particle motion in turbulent flow could be gained. Due to the complexity of the equation set, the 


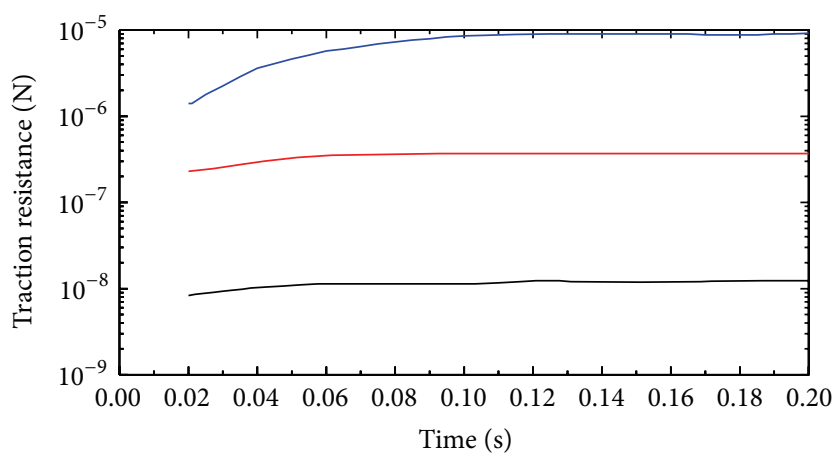

$\begin{aligned}-d & =250 \mu \mathrm{m} \\ -d & =50 \mu \mathrm{m} \\ -d & =10 \mu \mathrm{m}\end{aligned}$

(a) Traction resistance

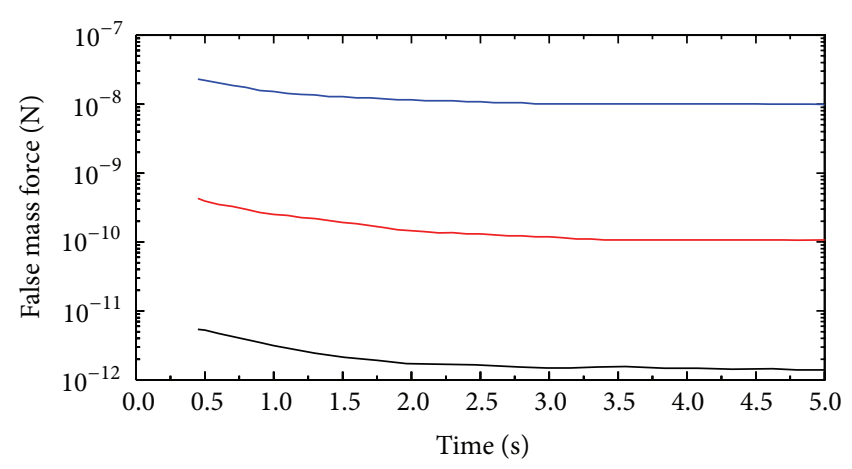

$\begin{aligned}-d & =250 \mu \mathrm{m} \\ -d & =50 \mu \mathrm{m} \\ -d & =10 \mu \mathrm{m}\end{aligned}$

(b) False mass force

FIGURE 2: Changes of traction resistance and false mass force with time.

relationship between coal ash particle velocity and time needed to use the numerical analysis computer software.

\section{Numerical Simulation of Coal Ash Particle Movement}

For solving nonlinear differential equation, numerical solution commonly uses Matlab software. When solving differential equation without analytical solution, the general solution for Matlab is Rung-Kutta middle order method [23]. When higher accuracy is required, Matlab uses a multistep Adams-Bashforth-Moulton method [24]. Numerical difference method is used to solve differential equation that is difficult to solve. In this study, Rung-Kutta fourth-order and fifth-order methods were used to solve the nonlinear differential equation of the particle motion mathematical model.

3.1. Force Analysis of Various Diameter Coal Ash Particles in the Airflow. Take coal ash particle sizes of $10 \mu \mathrm{m}, 50 \mu \mathrm{m}$, and $250 \mu \mathrm{m}$ to calculate and investigate its force conditions. Set airflow as the direct translation flow, the average airflow velocity as $20 \mathrm{~m} / \mathrm{s}$, the amplitude of pulsating flow velocity as $5 \mathrm{~m} / \mathrm{s}$, the turbulent fluctuation frequency as $1000 \mathrm{rad} / \mathrm{s}$, the density of airflow as $1.29 \mathrm{~kg} / \mathrm{m}^{3}$, and the density of coal ash particle as $2400 \mathrm{~kg} / \mathrm{m}^{3}$. The changes of traction resistance and false mass force with time drawn from (5) and (8) were shown in Figure 2. Gravity, buoyancy, and pressure gradient force were shown in Table 1.

For the various diameter coal ash particles, the magnitude difference of force was between $10^{2}$ and $10^{3}$ when the particle size difference was 5 times. For different forces of the same kind of particles, taking $50 \mu \mathrm{m}$ particles as an example, magnitude of traction resistance was the maximum of $10^{-7}$. Obviously, traction resistance had significant impact on the particles. False mass force was $10^{-7}$, gravity was $10^{-9}$, buoyancy was $10^{-13}$, and pressure gradient force was $10^{-13}$. For the force change trends with time, due to the use of
TABLE 1: Gravity, buoyancy, and pressure gradient force of various diameter coal ash particles.

\begin{tabular}{lcccc}
\hline Forces $(\mathrm{N})$ & Symbol & $10 \mu \mathrm{m}$ & $50 \mu \mathrm{m}$ & $250 \mu \mathrm{m}$ \\
\hline Gravity & $F_{g}$ & $1.28 \times 10^{-11}$ & $1.6 \times 10^{-9}$ & $7.2 \times 10^{-6}$ \\
Buoyancy & $F_{f}$ & $6.15 \times 10^{-15}$ & $7.7 \times 10^{-13}$ & $3.4 \times 10^{-10}$ \\
Pressure gradient force & $F_{p}$ & $6.5 \times 10^{-15}$ & $8.0 \times 10^{-13}$ & $1.0 \times 10^{-10}$ \\
\hline
\end{tabular}

logarithmic coordinates, the overall trends of the force were relatively smooth. Traction resistance showed a slight upward trend, and the false mass force showed a slight downward trend.

3.2. Separation Parameters for Various Diameter Coal Ash Particles. According to the preliminary planning of experimental equipment design, three coal ash particle sizes as $10 \mu \mathrm{m}, 50 \mu \mathrm{m}$, and $250 \mu \mathrm{m}$ should be classified. Therefore, the key design was to calculate the airflow velocities for keeping the three different particles at steady conditions. Then the diameter of separation equipment could be obtained from the relevant airflow velocity.

Importing (11) and (12) into Matlab programming, through changing the airflow velocity, the classification conditions of three different particles could be determined basically. Figure 3 was partial results of coal ash particles under different airflow velocity.

Figure 4 was parts of numerical simulation results of three coal ash particles movement velocities when airflow velocity changed from 0.06 to $3 \mathrm{~m} / \mathrm{s}$. The overall velocity trends of three particles in airflow field increased with airflow velocity. When the airflow velocity was $0.06 \mathrm{~m} / \mathrm{s}$, three particles were basically at a static state. When the airflow velocity reached $0.3 \mathrm{~m} / \mathrm{s}, 10 \mu \mathrm{m}$ particles started to move and gradually achieved the basically stable suspension. The velocity variation range was about $0.2 \mathrm{~m} / \mathrm{s}$. When the airflow velocity reached $1.38 \mathrm{~m} / \mathrm{s}, 50 \mu \mathrm{m}$ particles were in a stable suspension state and fluctuated with a velocity range of $0.2 \mathrm{~m} / \mathrm{s}$. But at this time $10 \mu \mathrm{m}$ particles had already risen at 

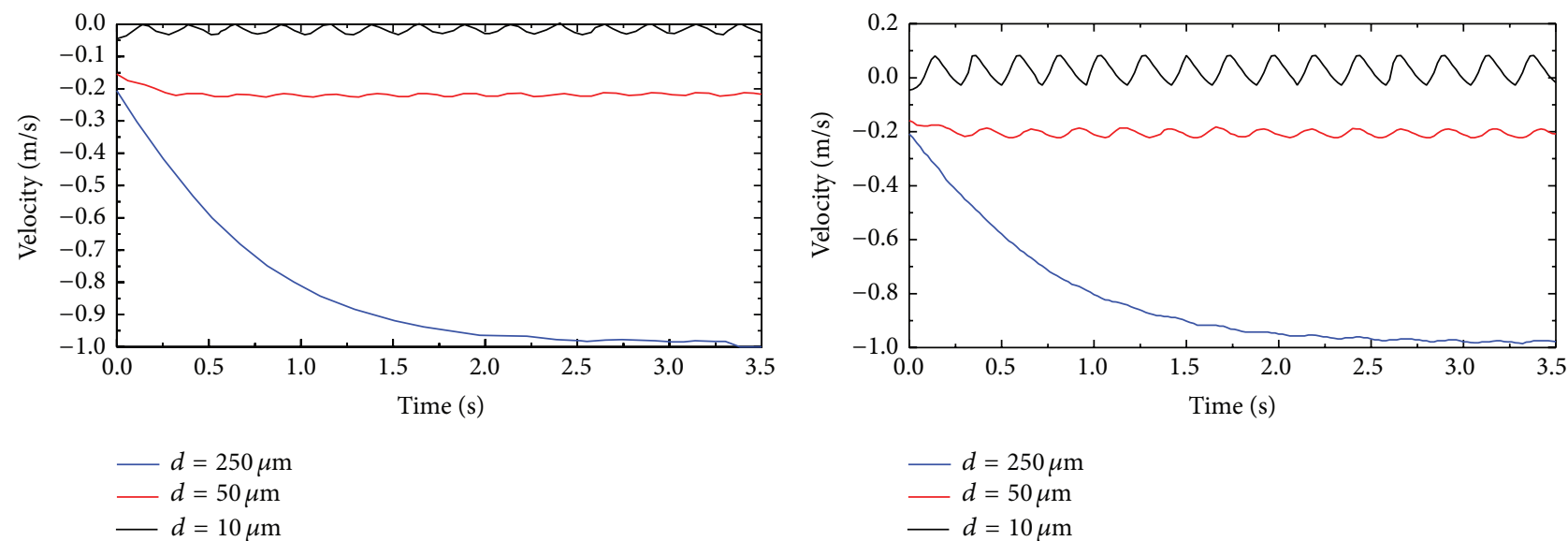

$$
\begin{aligned}
-d & =250 \mu \mathrm{m} \\
-d & =50 \mu \mathrm{m} \\
-d & =10 \mu \mathrm{m}
\end{aligned}
$$

(a) $v_{g p}=0.06 \mathrm{~m} / \mathrm{s}$

(b) $v_{g p}=0.3 \mathrm{~m} / \mathrm{s}$
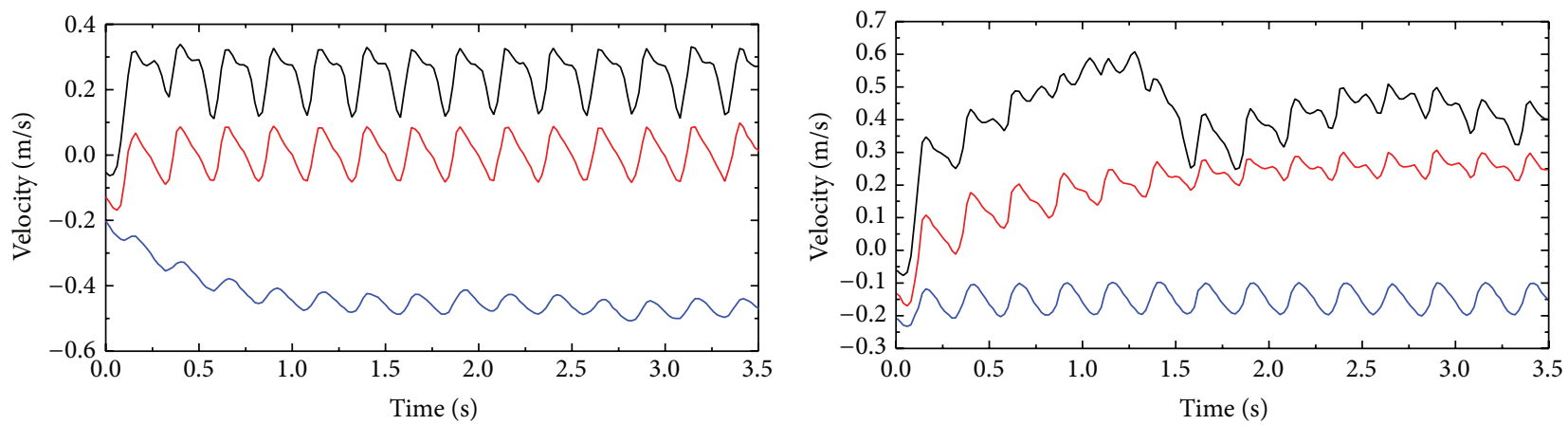

$\begin{aligned}-d & =250 \mu \mathrm{m} \\ -d & =50 \mu \mathrm{m} \\ -d & =10 \mu \mathrm{m}\end{aligned}$

$$
\begin{aligned}
-d & =250 \mu \mathrm{m} \\
-d & =50 \mu \mathrm{m} \\
-d & =10 \mu \mathrm{m}
\end{aligned}
$$

(c) $v_{g p}=1.38 \mathrm{~m} / \mathrm{s}$

(d) $v_{g p}=1.98 \mathrm{~m} / \mathrm{s}$

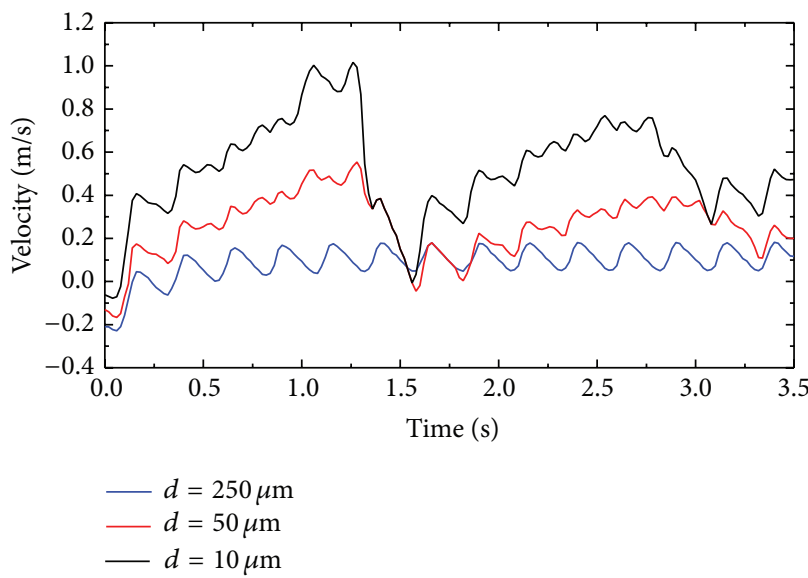

(e) $v_{g p}=2.46 \mathrm{~m} / \mathrm{s}$

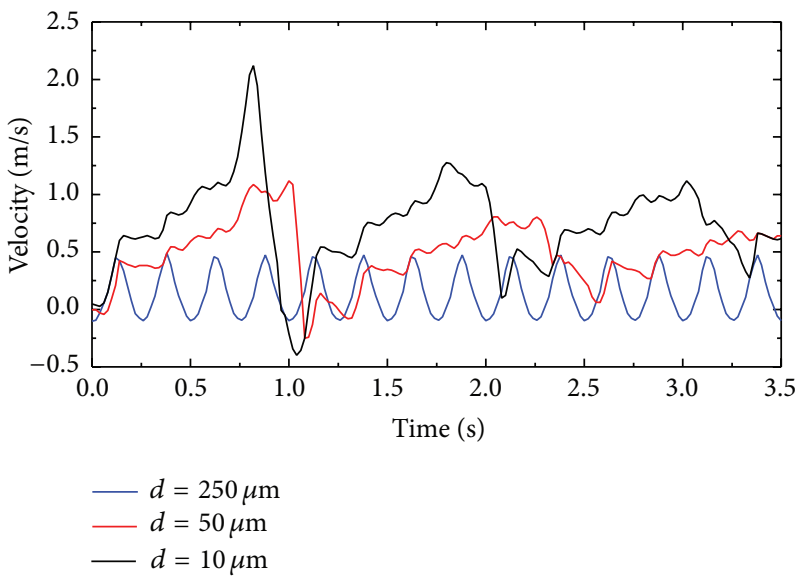

(f) $v_{g p}=3.00 \mathrm{~m} / \mathrm{s}$

FIGURE 3: Coal ash particle velocity under different airflow velocity.

the speed of $0.2 \mathrm{~m} / \mathrm{s}$. However, $250 \mu \mathrm{m}$ particles were still in a quiescent state in theory (a small amount of $250 \mu \mathrm{m}$ particles had already been drawn out by the airflow in the actual situation). When the airflow velocity reached $1.98 \mathrm{~m} / \mathrm{s}, 10 \mu \mathrm{m}$ particles began to present an erratic state. When the airflow velocity was $2.46 \mathrm{~m} / \mathrm{s}, 250 \mu \mathrm{m}$ particles reached a suspending steady state. And the velocity change range was still about $0.2 \mathrm{~m} / \mathrm{s}$. However, the other two particles were in completely unstable state. So, for the three different diameters of coal ash particles $(10 \mu \mathrm{m}, 50 \mu \mathrm{m}$, and $250 \mu \mathrm{m})$, the separation 


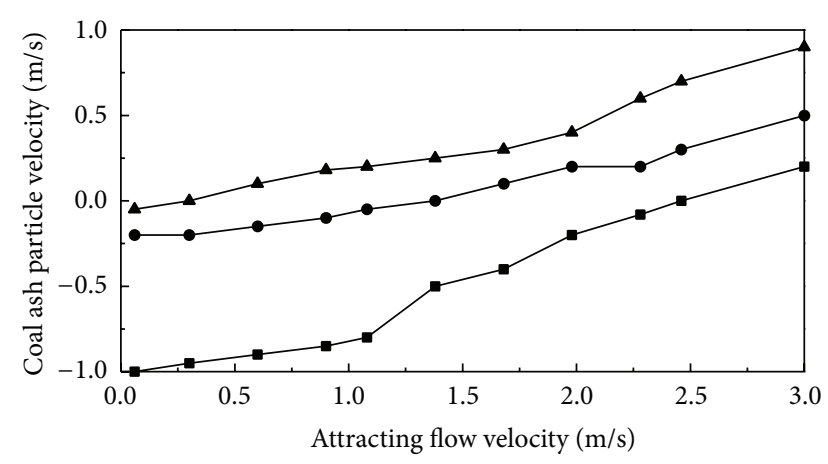

$\multimap d=250 \mu \mathrm{m}$
$\multimap d=50 \mu \mathrm{m}$
$\multimap d=10 \mu \mathrm{m}$

FIGURE 4: Relationships between coal ash particle average velocity and airflow velocity.

airflow velocities (attracting velocity) in theory were $0.3 \mathrm{~m} / \mathrm{s}$, $1.38 \mathrm{~m} / \mathrm{s}$, and $2.46 \mathrm{~m} / \mathrm{s}$. From Figure 4 , it could be found that the movement velocity of coal ash particles increased about $0.1 \sim 0.5 \mathrm{~m} / \mathrm{s}$ when the airflow velocity increased $0.5 \mathrm{~m} / \mathrm{s}$. The increasing amplitude of coal ash particle velocity increased with the increase in airflow velocity. The increasing amplitude of big coal ash particles velocity was slightly larger than that of the small particles.

Figure 5 showed the relationships between the pulsating amplitude of coal ash particle velocity and airflow velocity. The pulsating amplitude of coal ash particle velocity increased with the increase in airflow velocity. When the airflow velocity was less than $2.0 \mathrm{~m} / \mathrm{s}$, the pulsating amplitude of coal ash particle velocity was not obvious. When the airflow velocity was more than $2.0 \mathrm{~m} / \mathrm{s}$, the pulsating amplitude of three coal ash particles increased obviously. In this situation, smaller particles presented larger pulsating amplitude and irregular local velocity. On the contrary, larger particles showed smaller pulsating amplitude and regular local velocity. When the airflow velocity was more than $2.0 \mathrm{~m} / \mathrm{s}$, the average pulsating amplitudes were $2 \mathrm{~m} / \mathrm{s}, 1 \mathrm{~m} / \mathrm{s}$, and $0.3 \mathrm{~m} / \mathrm{s}$ for the particles of $10 \mu \mathrm{m}, 50 \mu \mathrm{m}$, and $250 \mu \mathrm{m}$.

3.3. Effects of Jet Flux on Coal Ash Reclaiming. The coal ash collecting and grading system designed in this study worked as the following principle. The jet airflow firstly stirred coal ash to form a fluidization domain. And then the attracting pipe would extract coal ash. The coal ash would be graded and separated in the device. As a result, the state of fluidization domain played an important role in coal ash collecting and grading process. In the study, Fluent software under Eulerian-Eulerian model was used to simulate twophase flow. The fluidization domain shape of coal ash under different jet flux was simulated to determine the quality of fluidization performance and then determine the required jet flux. Figure 6 shows the fluidization domain shape of coal ash under different jet flux. The colorful coordinate presented the volume fraction of coal ash.

As shown in Figure 6(a), when jet flux was $0.05 \mathrm{~m}^{3} / \mathrm{h}$, the fluidization domain developed in both horizontal and

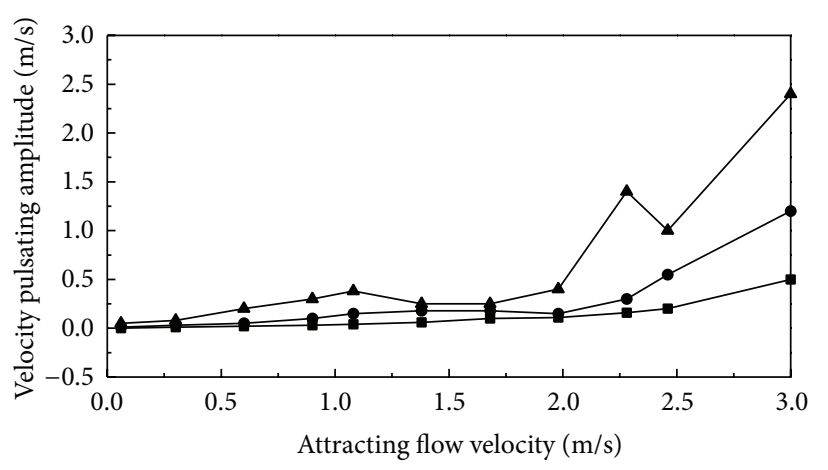

$$
\begin{aligned}
& \multimap d=250 \mu \mathrm{m} \\
& \multimap d=50 \mu \mathrm{m} \\
& \smile d=10 \mu \mathrm{m}
\end{aligned}
$$

FIGURE 5: Relationships between coal ash particle velocity pulsating amplitude and airflow velocity.

vertical direction. But, relatively speaking, it had a better development in horizontal direction than in vertical direction. Though coal ash could be efficiently fractionated under this flux (proved in Section 4.2), the throughput of coal ash fractionation was very low.

As shown in Figure 6(b), when jet flux was $1.5 \mathrm{~m}^{3} / \mathrm{h}$, the fluidization domain achieved the best shape. This type of fluidization domain developed well in both horizontal and vertical direction. The fluidized shape of coal ash was rather clear. On the premise of meeting higher separation efficiency, this jet flux could achieve a higher throughput.

As shown in Figure 6(c), when jet flux was $3 \mathrm{~m}^{3} / \mathrm{h}$, the fluidization domain still developed well in both horizontal and vertical direction. Though the jet flux was large, the fractionation efficiency and the throughput were severely reduced. As can be seen in Figure 6(c), particle concentration of coal ash near the jet was particularly low under the strong jet airflow. Thereby, particles extracted by the attracting flow were very little. At the same time, due to the large jet velocity, the collision and interference among coal ash particles increased and the separation process was full of randomness. As a result, fractionation efficiency and throughput were reduced.

The simulation results showed that the fluidization domain of coal ash had a best fluidized state when jet flux was $1.5 \mathrm{~m}^{3} / \mathrm{h}$. So jet flux of $1.5 \mathrm{~m}^{3} / \mathrm{h}$ was used as a reference in the following experiments.

\section{Experimental Study of Coal Ash Collecting and Grading}

The structure of coal ash collecting and grading system designed in this study was shown in Figure 7 . The system was composed of air jet pipe, dust cover, suspension chambers, settling chambers, blinds, triangular storage rooms, discharging pipes, attracting pipe, and other components. When worked, the airflow went into system from intake pipe 1 , erupted from jet pipe 2, and then stirred up the coal ash and formed a fluidization domain. Dust cover 12 limited 


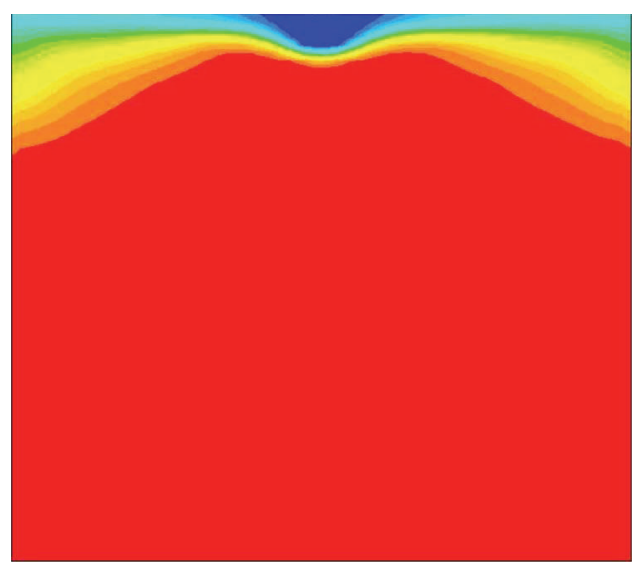

(a) Jet flux of $0.05 \mathrm{~m}^{3} / \mathrm{h}$

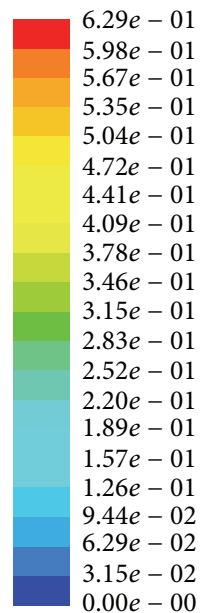

$0.00 e-00$

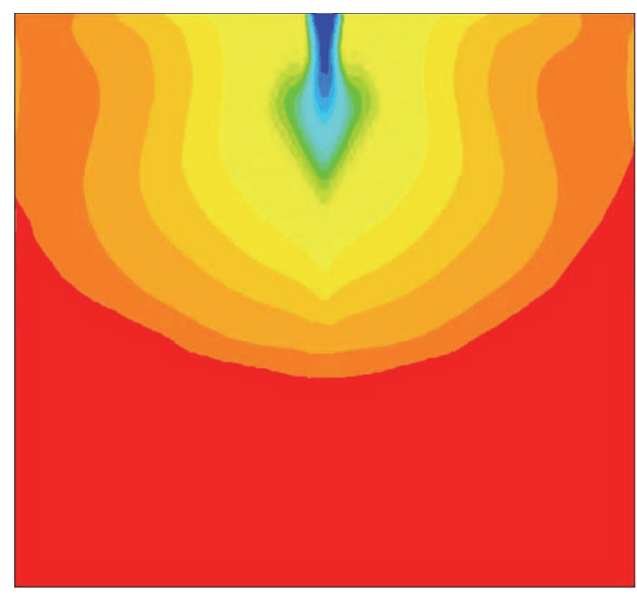

(b) Jet flux of $1.5 \mathrm{~m}^{3} / \mathrm{h}$

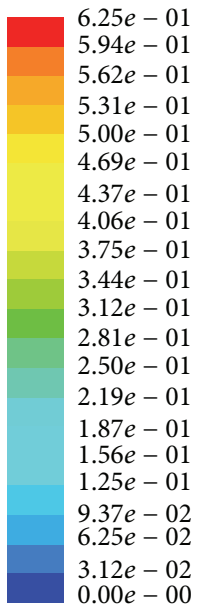

$6.23 e-01$

$5.92 e-01$

$5.61 e-01$

$5.30 e-01$

$4.99 e-01$

$4.67 e-01$

$4.36 e-01$

$4.05 e-01$

$3.74 e-01$

$3.43 e-01$

$3.12 e-01$

$2.80 e-01$

$2.49 e-01$

$2.18 e-01$

$1.87 e-01$

$1.56 e-01$

$1.25 e-01$

$9.35 e-02$

$9.35 e-02$
$6.23 e-02$

$3.12 e-02$

$0.00 e-00$

(c) Jet flux of $3 \mathrm{~m}^{3} / \mathrm{h}$

FIGURE 6: Fluidization domain shape of coal ash under different jet flux.

the fluidized coal ash to stretch all around. The pressure in dust cover 12 would rise with the continuous entering of jet airflow. At the same time, the attracting pipe 21 showed an attracting effect. The fluidized coal ash would move upwards and enter into stair-like pipes. With the increasing diameter of the stair-like pipes, the coal ash flow velocity decreased. Meanwhile, particles with large density or big size carried by airflow could not move along the pipe any more. They would suspend in suspension chambers $(14,16,18$, and 20$)$ or settle along the pipe wall of settling chambers $(15,17$, and 19). Sediment particles gathered in triangular storage rooms (5, 8, and 11) through blinds (3, 6, and 9). The gathered coal ash particles were extracted slowly through discharge pipes $(4,7$, and 10) under the negative pressure. This process accelerated the settling velocity of particles near the settling chambers $(15,17$, and 19) wall and the moving velocity of suspended particles to the pipe wall in suspension chambers $(14,16,18$, and 20). Three grading areas with progressively increased diameter were designed in stair-like pipe to separate coal ash. The particles would be drawn out from discharge pipes $(4,7$, and 10$)$ at the particle size order from big to small. The last remaining coal ash particles with small size would be extracted through attracting pipe 21 . Coal ash particles extracted from discharge pipes (4, 7, and 10) and attracting pipe 21 were separated into gas and solid by a cyclone separator. Finally, this system achieved the collecting, grading, and transferring of coal ash simultaneously. Figure 8 is the schematic diagram of the whole separator system.

The simulation results in Section 3.2 showed that the attracting airflow velocities to keep the coal ash particles of $10 \mu \mathrm{m}, 50 \mu \mathrm{m}$, and $250 \mu \mathrm{m}$ at steady conditions were $0.3 \mathrm{~m} / \mathrm{s}, 1.38 \mathrm{~m} / \mathrm{s}$, and $2.46 \mathrm{~m} / \mathrm{s}$, respectively. According to the continuity equation, the airflow in separation unit was constant and the total airflow through each level was equal. So the continuity equation was

$$
Q_{1}=Q_{2}=Q_{3}=v \pi\left(\frac{D}{2}\right)^{2}
$$

In this equation, $Q_{1}$ was the airflow flux in the first stage $\left(\mathrm{m}^{3} / \mathrm{s}\right) ; Q_{2}$ was the airflow flux in the second stage $\left(\mathrm{m}^{3} / \mathrm{s}\right)$; 


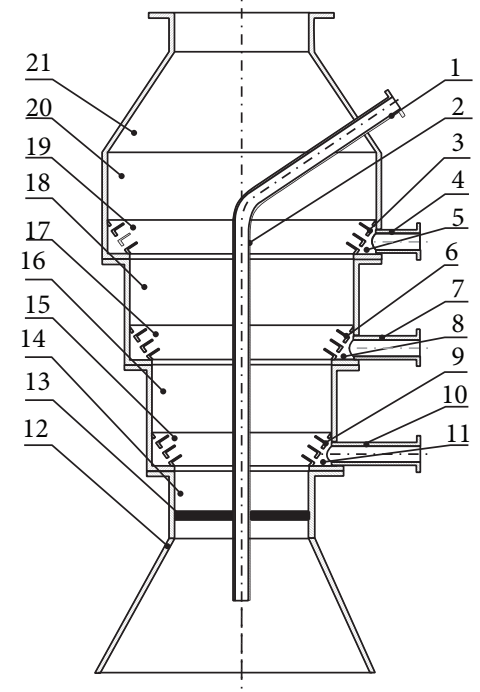

FIGURE 7: Structure of coal ash separator. 1: intake pipe; 2: jet pipe; 3, 6, and 9: blinds; 4, 7, and 10: discharge pipes; 5, 8, and 11: triangular storage rooms; 12 : dust cover; 13 : jet pipe clamp bracket; $14,16,18$, and 20: suspension chambers; 15,17 , and 19: settling chambers; 21 : attracting pipe.

$Q_{3}$ was the airflow flux in the third stage $\left(\mathrm{m}^{3} / \mathrm{s}\right) ; v$ was the airflow velocity $(\mathrm{m} / \mathrm{s}) ; D$ was the pipe diameter $(\mathrm{m})$.

In this study, the pipe diameter of the first stage $D_{1}$ was $100 \mathrm{~mm}$. So $Q_{1}=Q_{2}=Q_{3}=0.0193 \mathrm{~m}^{3} / \mathrm{s}, D_{2}=133 \mathrm{~mm}$, and $D_{3}=286 \mathrm{~mm}$ according to (13). The study also set the height of each suspension chamber $(14,16,18$, and 20) to $100 \mathrm{~mm}$, set the height of each settling chamber $(15,17$, and 19) to $50 \mathrm{~mm}$, and set the inner diameter of jet pipe to $8 \mathrm{~mm}$.

4.1. Separation Efficiency Calculation. Separation efficiency was the efficiency that the separator graded raw coal ash with particles size of $45 \mu \mathrm{m}$ as critical point [25]. Therefore, evaluation of the separation efficiency mainly depended on the percentage of particles (diameter $\leq 45 \mu \mathrm{m}$ ) in cinder and the percentage of particles (diameter $>45 \mu \mathrm{m}$ ) in fine ash. Then, separation efficiency could be calculated.

The raw coal ash was assumed as $100 \%$ (Figure 9). The percentage of particles (diameter $>45 \mu \mathrm{m}$ ) in raw coal ash was assumed as $A(\%)$.

The percentage of particles (diameter $>45 \mu \mathrm{m}$ ) in fine ash was assumed as $B(\%)$. The percentage of particles (diameter $\leq 45 \mu \mathrm{m})$ in cinder was assumed as $C(\%)$. According to the assumption, $A$ was theoretical amount of cinder and $100-A$ was theoretical amount of fine ash. Collection efficiency of the cyclone separator is assumed as $\eta_{x}$; thus, separation efficiency could be calculated according to

$$
\eta=\frac{(100-A)-[(100-A) \times B+A \times(100-C)] / 100}{100-A} \times \eta_{x} .
$$

In this equation, $\eta$ was separation efficiency $(\%),(100-A) \times B$ was the number of particles (diameter $>45 \mu \mathrm{m}$ ) in fine ash, and $A \times(100-C)$ was the number of particles (diameter $\leq$ $45 \mu \mathrm{m})$ in cinder.

4.2. Effects of Jet Flux on Separation Efficiency. The selected coal ash sample was put into the ash bucket. The attracting flux was set to $70 \mathrm{~m}^{3} / \mathrm{h}$. By changing the jet flux $\left(0.3 \mathrm{~m}^{3} / \mathrm{h}\right.$, $0.7 \mathrm{~m}^{3} / \mathrm{h}, 1.1 \mathrm{~m}^{3} / \mathrm{h}, 1.5 \mathrm{~m}^{3} / \mathrm{h}, 1.9 \mathrm{~m}^{3} / \mathrm{h}, 2.3 \mathrm{~m}^{3} / \mathrm{h}$, and $2.7 \mathrm{~m}^{3} / \mathrm{h}$ ), separation efficiencies at 7 different jet fluxes had been studied. Figure 10 showed the particle size distribution of coal ash at the exit of different grading stages when jet flux was $1.5 \mathrm{~m}^{3} / \mathrm{h}$.

As shown in Figure 10, the particle size of coal ash that was separated during the first stage distributed from $200 \mu \mathrm{m}$ to $300 \mu \mathrm{m}$. The particle size of coal ash that was separated during the second stage substantially distributed from $10 \mu \mathrm{m}$ to $100 \mu \mathrm{m}$. The particle size of coal ash that was separated during the third stage mainly concentrated nearby $10 \mu \mathrm{m}$, but the overall particle size distribution was dispersed. These results indicated that the smaller the particle size of coal ash, the worse the grading effect.

Figure 11 showed the particles' separation efficiency under different jet fluxes. When the jet flux was less than $1.5 \mathrm{~m}^{3} / \mathrm{h}$, with the jet flux increasing, the separation efficiency of coal ash changed little and remained at about $73 \%$. However, with the continuous increasing of jet flux, separation efficiency decreased dramatically and reduced to about $45 \%$. This could be explained as follows. When jet flux was relatively small, it only had an obvious effect on the fluidization domain shape of coal ash but had little effect on the particles' vertical motion. When jet flux was too large, coal ash directly entered into the separator under the high pressure and played an important role in affecting the attracting flux. As a result, attracting flux lost its effect on coal ash, and the classifying effect of coal ash dramatically deteriorated. Experimental results showed that a large jet flux also led to coal ash splashing and then resulted in environmental pollution. From a practical point of view, although separation efficiency was higher at small attracting flux, total grading throughput of coal ash in unit time was relatively low due to the low coal ash particle concentration. Taking separation efficiency and grading throughput into account, the optimal jet flux was $1.5 \mathrm{~m}^{3} / \mathrm{h}$ in this study.

4.3. Effect of Attracting Flux on Separation Efficiency. To study the effect of attracting flux to separation efficiency of coal ash, jet flux was set to $1.5 \mathrm{~m}^{3} / \mathrm{h}$. By changing attracting flux (20, $30,50,70,90,110$, and $120 \mathrm{~m}^{3} / \mathrm{h}$ ), the separation efficiencies under 7 different attracting fluxes were investigated. Figure 12 was the separation efficiencies under 7 different attracting fluxes.

As shown in Figure 12, with the increases in attracting flux, the separation efficiency of coal ash grading device increased significantly. When attracting flux increased to $70 \mathrm{~m}^{3} / \mathrm{h}$, separation efficiency reached the maximum of $74 \%$. When attracting flux continued to increase, the separation efficiency presented a significant decline. The low separation efficiency under small attracting flux was due to the impact of the airflow velocity of the attracting flow. The coal ash 


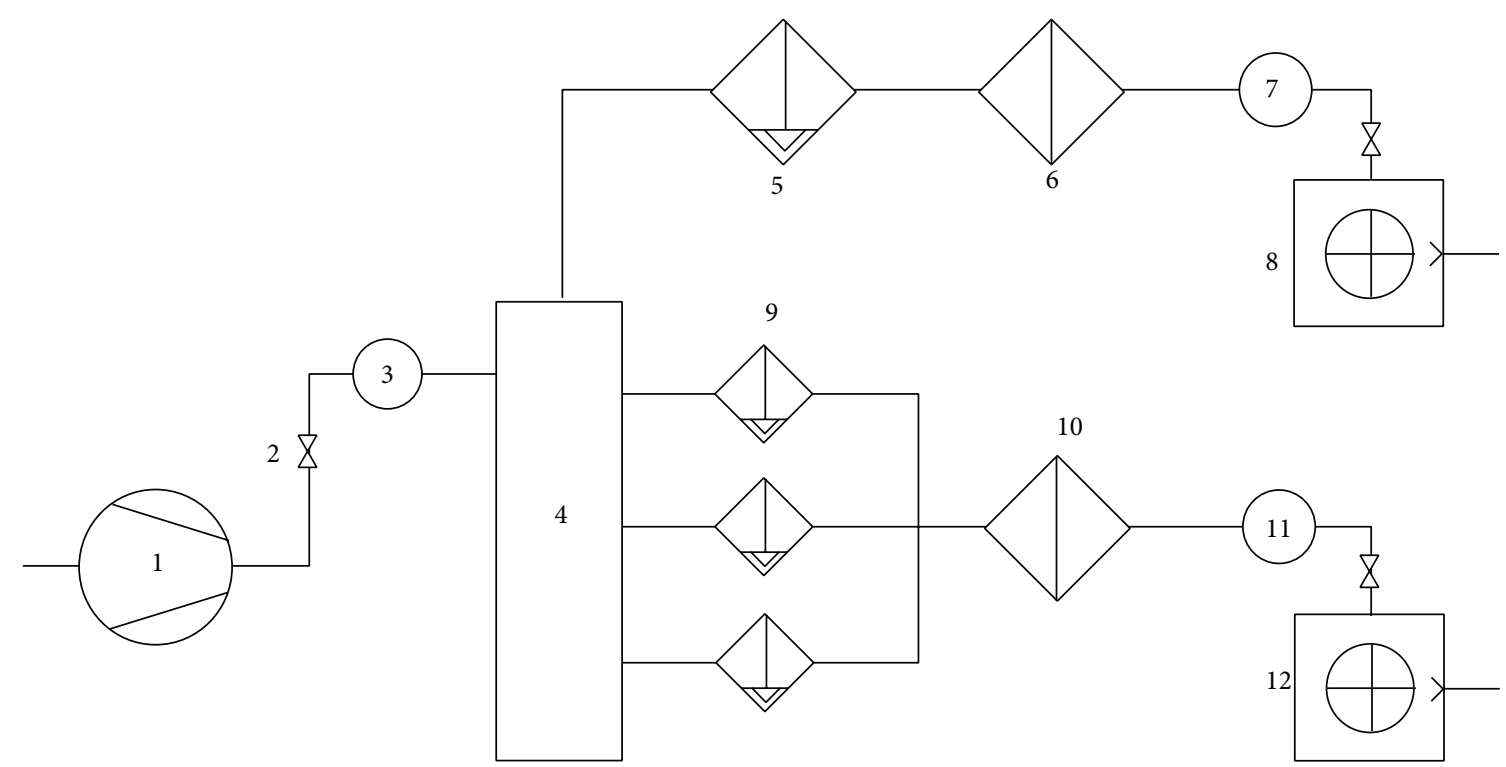

FIGURE 8: Schematic diagram of coal ash separator system. 1: air compressor; 2: airflow control valve; 3, 7, and 11: air flow meters; 4: coal ash separator; 5 and 9: cyclone separators; 6 and 10: filter units; 8 and 12: water ring vacuum pumps.

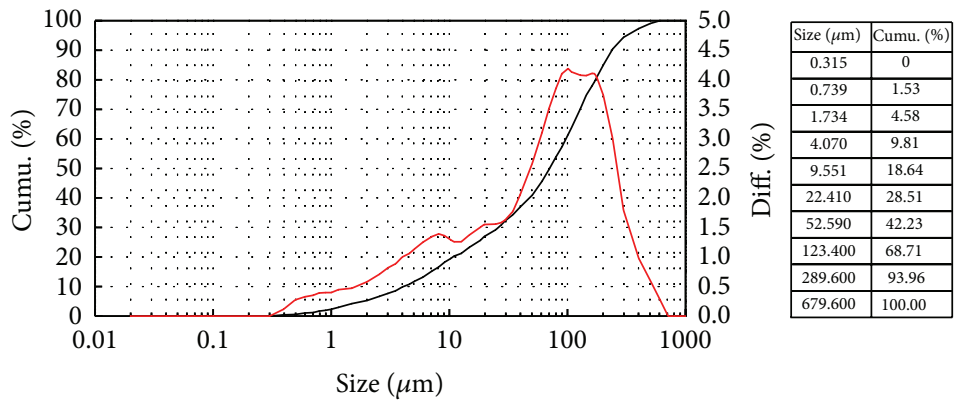

FIGURE 9: Particle size distribution of raw coal ash.

particles were affected by several forces and the low airflow velocity could not attract large particle. Many small particles $(\leq 45 \mu \mathrm{m})$ were extracted out in the first grading stage and resulted in low separation efficiency. With the increase in attracting flux, the updraft velocity increased. Many big particles could be lift up and a clear increase in separation efficiency occurred. When attracting flux exceeded $70 \mathrm{~m}^{3} / \mathrm{h}$, the overlarge flux resulted in deterioration of particle dispersibility and serious particle agglomeration. A lot of coal ash particles were pumped directly into the cyclone separators and filter units without grading. Due to the instability of particle agglomeration effects and the violent particle collision, the separation effect of each grading stage dropped, resulting in the decrease of separation efficiency. In this study, the optimal attracting flux was $70 \mathrm{~m}^{3} / \mathrm{h}$.

4.4. Effect of Separation Time on Separation Efficiency. The attracting flux was set to $70 \mathrm{~m}^{3} / \mathrm{h}$ and the jet flux was set to $1.5 \mathrm{~m}^{3} / \mathrm{h}$. The effects of separation time on separation efficiency were examined, seen in Figure 13. Under a certain jet flux and attracting flux, the coal ash separation efficiency gradually increased with separation time. When separation time reached $10 \mathrm{~s}$, the separation efficiency was about $73 \%$ and kept steady. When separation time reached about $25 \mathrm{~s}$, the separation efficiency presented another small increase, followed by a sharp dropping to about $60 \%$. This phenomenon could be explained as follows. With the increase in separation time, the coal ash concentration gradually increased, and separation efficiency also gradually increased. Because of the fixing position of grading device, the fluidization domain of coal ash gradually becomes a stable concave shape; therefore, the separation efficiency was in a relatively stable value. With the continuing of grading process, the amount of coal ash reduced and less coal ash could be attracted into grading device, resulting in a small increase and a sharp decrease in separation efficiency. In practical operation, the grading device would do the horizontal or vertical movement to achieve the stable separation efficiency and the continuous coal ash collecting and grading effect. In this study, the optimal separation time was $15 \mathrm{~s}$. 

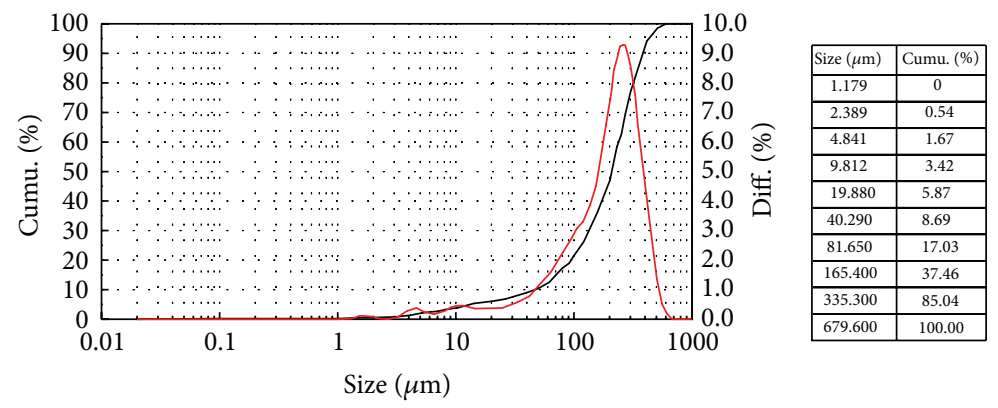

(a) In the first stage

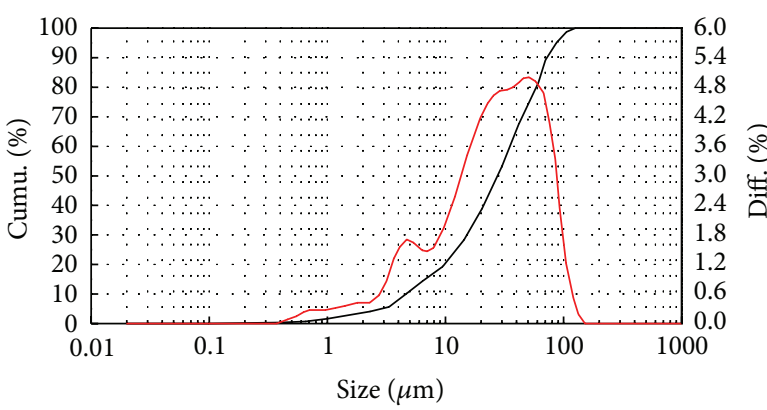

\begin{tabular}{|c|c|}
\hline Size $(\mu \mathrm{m})$ & Cumu. (\%) \\
\hline 0.400 & 0 \\
\hline 0.768 & 0.89 \\
\hline 1.477 & 2.57 \\
\hline 2.838 & 4.89 \\
\hline 5.453 & 12.21 \\
\hline 10.480 & 21.20 \\
\hline 20.130 & 38.81 \\
\hline 38.690 & 64.20 \\
\hline 74.360 & 90.63 \\
\hline 142.900 & 100.00 \\
\hline
\end{tabular}

(b) In the second stage
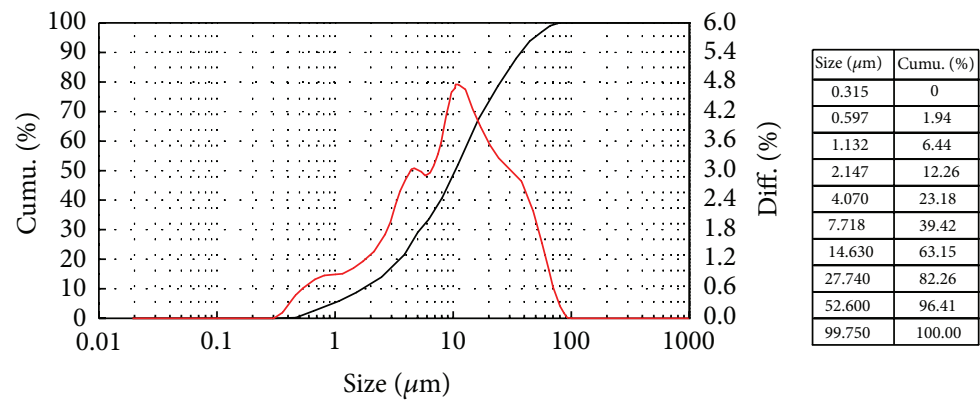

(c) In the third stage

Figure 10: Particle size distribution of coal ash (jet flux $=1.5 \mathrm{~m}^{3} / \mathrm{h}$ ) in different grading stages.

4.5. Comparison of Experimental and Theoretical Average Separated Particle Size. The median diameter of separated coal ash (average particle size) was an important indicator for evaluating grading perfection in the coal ash grading process. The jet flux was selected as $1.5 \mathrm{~m}^{3} / \mathrm{h}$ and the separation time was $15 \mathrm{~s}$. The change of the average separated particle size of the first separation exit was measured under different attracting velocity (controlled by attracting flux) and was compared with the theoretical value (in Figure 14). The reason to study the first separation exit was that the first separation exit was proved to be the smallest affected by tiny particles less than $50 \mu \mathrm{m}$ and to have the most shallow particle size distribution.

As can be seen in Figure 14, under a certain jet flux, separated coal ash particle size gradually increased with the increase in attracting velocity. In the change process of attracting velocity from 0 to $3 \mathrm{~m} / \mathrm{s}$, the average separated particle size gradually increased from $20 \mu \mathrm{m}$ to $260 \mu \mathrm{m}$. The experimental results were consistent with the basic trend of theoretical results. When the attracting velocity was less than $1.5 \mathrm{~m} / \mathrm{s}$, the experimental results were slightly larger than the theoretical results. When the attracting velocity was greater than $1.5 \mathrm{~m} / \mathrm{s}$, the experimental values were less than the theoretical values, and the deviation became larger with the attracting velocity increase. This phenomenon was mainly caused by the different particle concentration in the grading device. When the attracting velocity was small, mutual interference between the particles was not serious and the particles were graded according to their own force. But a lot of small particles were in irregular movement and were likely to be directly extracted out from the attracting pipe. Therefore, the experimental values were larger than the theoretical values. When the attracting velocity became large, particle concentration increased within the grading device. Agglomeration and collision between particles enhanced. Many small particles were mixed into the first discharged pipe and then resulted in the relatively small average experimental separated particle size. 


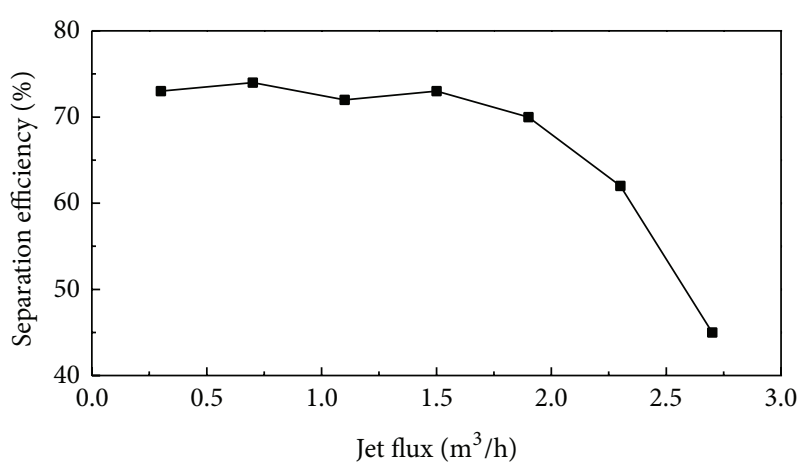

FIGURE 11: Separation efficiencies under different jet fluxes.

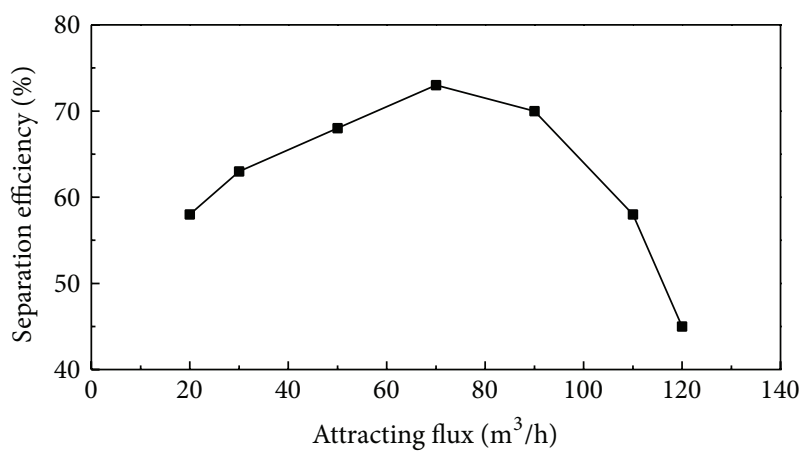

FIGURE 12: Separation efficiencies under different attracting fluxes.

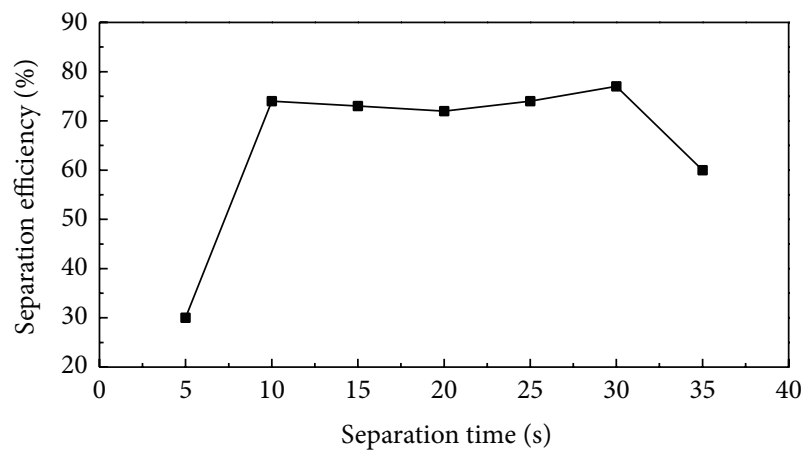

FIgURE 13: Separation efficiencies under different separation times.

\section{Conclusions}

Numerical simulation and experimental research on a new coal ash collecting and grading device were carried out. The following conclusions could be drawn.

(1) In the base of jet-attracting flow technology and gassolid two-phase flow theory, the force and motion of coal ash particles in gas flow were analyzed. The particle motion could be simplified to a onedimensional vertical movement. The following force as gravity, buoyancy, pressure gradient force, traction resistance, and false mass force had influence on particle movement. A mathematical model of coal ash particle motion was established.

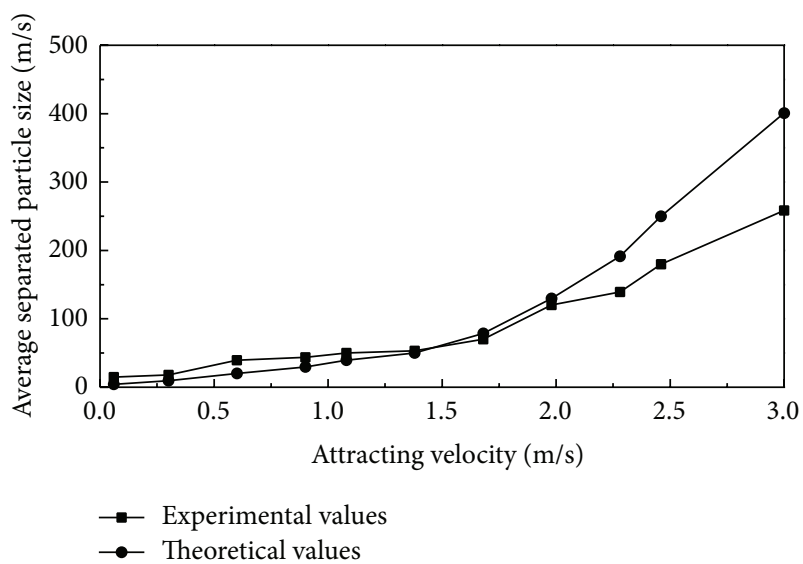

FIGURE 14: Comparison of experimental and theoretical results.

(2) The force of various sizes of coal ash particles was obtained through Matlab numerical simulations. By solving the coal ash particle motion mathematical model using Matlab, the separation conditions of different sizes of coal ash particles were simulated. And the theoretical airflow velocities of different particle size classification required were also determined. For coal ash particles of $10 \mu \mathrm{m}, 50 \mu \mathrm{m}$, and $250 \mu \mathrm{m}$, their theoretical classification airflow velocities were $0.3 \mathrm{~m} / \mathrm{s}, 1.38 \mathrm{~m} / \mathrm{s}$, and $2.46 \mathrm{~m} / \mathrm{s}$, respectively.

(3) The shape of nozzle fluidization domain under different jet flux was simulated using Fluent software. Taking the fluidization domain shape and the separation efficiency into account, the optimal jet flux was $1.5 \mathrm{~m}^{3} / \mathrm{h}$.

(4) Under the premise of the theoretical simulation, a coal ash collecting and grading device was established. The influence of jet flux, attracting flux, and separation time on separation efficiency was investigated. The optimal parameters were jet flux of $1.5 \mathrm{~m}^{3} / \mathrm{h}$, attracting flux of $70 \mathrm{~m}^{3} / \mathrm{h}$, and separation time of $15 \mathrm{~s}$.

(5) Theoretical values and experimental values of coal ash particles medium diameter in the first separation exit were compared. The reasons generating errors were analyzed. The trends of theoretical values and experimental values were basically the same. It proved the correctness of theoretical simulation and its guiding function to the experiment device design.

\section{Conflict of Interests}

The authors declare that there is no conflict of interests regarding the publication of this paper.

\section{Acknowledgments}

This study was jointly supported by National Natural Science Foundation of China (nos. 21107011, 51178098, and 31371873) 
and the Fundamental Research Funds for the Central Universities of China (nos. N100303006 and N130403001).

\section{References}

[1] L. Sun, "Hazard and treatment of haze weather," Environmental Science and Management, vol. 37, no. 10, pp. 71-75, 2012.

[2] G. Q. Han, J. W. Li, B. Du, J. Huang, and R. J. Wang, "Present status and future development of comprehensive utilization of coal ash," China Resource Comprehensive Utilization, vol. 24, no. 7, pp. 12-14, 2006.

[3] Q. P. Li and G. X. Shao, "evelopment of air classification technology," Chemical Equipment Technology, vol. 23, no. 5, pp. 1115, 2002.

[4] J. C. Li, Study of Classification Principle Based on Air-Solid Two-Phase Flow Theory and Its Application on SLK Coal Ash Classifier, Southwest University of Science and Technology, Mianyang, China, 2009.

[5] M. Q. Li, C. B. Wu, and Q. N. Liu, "The application of frequencyvaried turbo-classifier in the classification of coal ash," Coal Ash Comprehensive Utilization, vol. 1, pp. 34-36, 2004.

[6] F. Shi, "The art of the state of coal ash classification technology in china and probe into its developing prospects," Coal Ash China, vol. 3, pp. 41-44, 2004.

[7] J. W. Leonard, Coal Preparation, American, Institute of Mining, Metallurgical and Petroleum Engineers, New York, NY, USA, 4th edition, 1979.

[8] Z. Tong, N. Tsutomu, H. Yonggang, I. XYuanhua, and H. Jin, "Effect of particle properties on fluidization performance of sedimentary layer based on the spraying jet type sand collector the fundamental sutdy of a novel water bed pollutants collector," in Proceedings of the 4th IEEE Conference on Industrial Electronics and Applications (ICIEA '09), pp. 1093-1096, Xi'an, China, May 2009.

[9] T. Zhu, T. Nozaki, Y. H. Xie et al., "Dynamic model, and numerical simulation of particle motion in rotation flow field of centrifuge," in Proceedings of the 3rd International Symposium on Advances in Computation and Intelligence (ISICA '08), vol. 12, pp. 470-478, Wuhan, China, 2008.

[10] T. Zhu, T. Nozaki, Y. H. Xie, J. Han, and J. Jiang, "Numerical simulation and visualization experiment of solid particle motion affected by parameters of flow in tapered drum rotating type separator," in Proceedings of the 7th International Conference on System Simulation and Scientific Computing (ICSC '08), pp. 867871, Beijing, China, October 2008.

[11] T. Zhu, J. Han, T. Nozaki, Y. H. Xie, and M. Y. You, "Characteristics of collecting efficiency related to spraying jet flux and suction flux in spraying jet type collector," in Proceedings of the 6th International Conference on Material Handling (ICMH '08), pp. 268-272, Shanghai, China, October 2008.

[12] D. Y. Fang, Two-Phase Flow Dynamics, National University of Defense Technology Publishing, Changsha, China, 1988.

[13] L. Z. Zhang, Y. Z. Li, and G. J. Wang, "Study on particle flow character in gas/solid two-phase wind tunnel," Journal of System Simulation, vol. 19, no. 14, pp. 3200-3202, 2007.

[14] K. F. Cen, Gas-Solid Separation Theory and Technology, Zhejiang University Press, Hangzhou, China, 1999.

[15] Y. L. MA. Numerical simulation, Numerical Simulation of High Concentrations of Gas-Solid Two Phase Flow, Zhejiang University, Hangzhou, China, 2001.
[16] K. F. Cen and J. R. Fan, "The analysis of the forces acting on coal particles and the trajectories in the gas flow," Journal of Zhejiang University, vol. 21, no. 6, pp. 1-11, 1987.

[17] D. Y. Liu, Two-Phase Hydrodynamics, Higher Education Press, Beijing, China, 1993.

[18] M. Nakagawa, T. Matumi, H. Takeuchi, and N. Kokubo, "Mixing of the confined jet of mist flow," JSME International Journal B: Fluids and Thermal Engineering, vol. 39, no. 2, pp. 381-386, 1996.

[19] Y. S. Wang, Numerical Calculation and Experimental Study of Particle Motion in Jet Flow Sand Water Collectortor, Northeastern University, Shenyang, China, 2010.

[20] Y. Q. Xiong, M. Y. Zhang, Z. L. Yuan, and D. M. Xue, “Three-dimensional numerical simulation on gas-solid two-phase flows in gas-solid injector," Proceedings of the Chinese Society of Electrical Engineering, vol. 25, no. 20, pp. 77-82, 2005.

[21] K. Z. Qiu, X. D. Li, J. H. Yan, Y. Chi, M. J. Ni, and K. F. Cen, "The experiment research of gas-solid interaction in horizontal flow boundary layer," Chinese Journal of Theoretical Applied Mechanics, vol. 31, no. 4, pp. 456-465, 1999.

[22] J. R. Xu and Q. Luo, "The relative motion between the two phases of the solid-liquid hydrocyclone," Chinese Journal of Nonferrous Metals, vol. 8, no. 4, pp. 132-135, 1998.

[23] Y. Z. Meng, MATLAB 5.X Application Skills, Science Press, Beijing, China, 1999.

[24] Y. Cui, MATLAB 5.3 Projects Explanation, Aerospace Industry Press, Beijing, China, 1999.

[25] Y. Shi and X. C. Lin, "Three-dimensional numerical simulation of gas-solid injector based on Fluent," Coal Preparation Technology, vol. 4, pp. 19-23, 2011. 


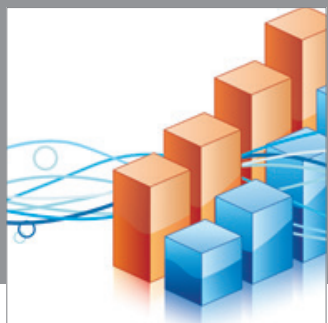

Advances in

Operations Research

mansans

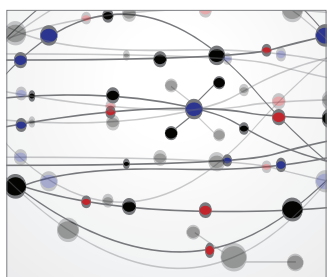

The Scientific World Journal
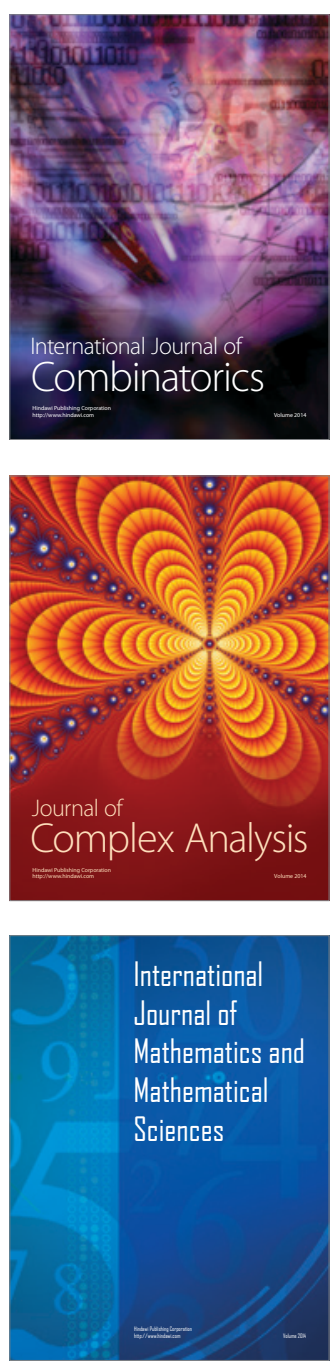
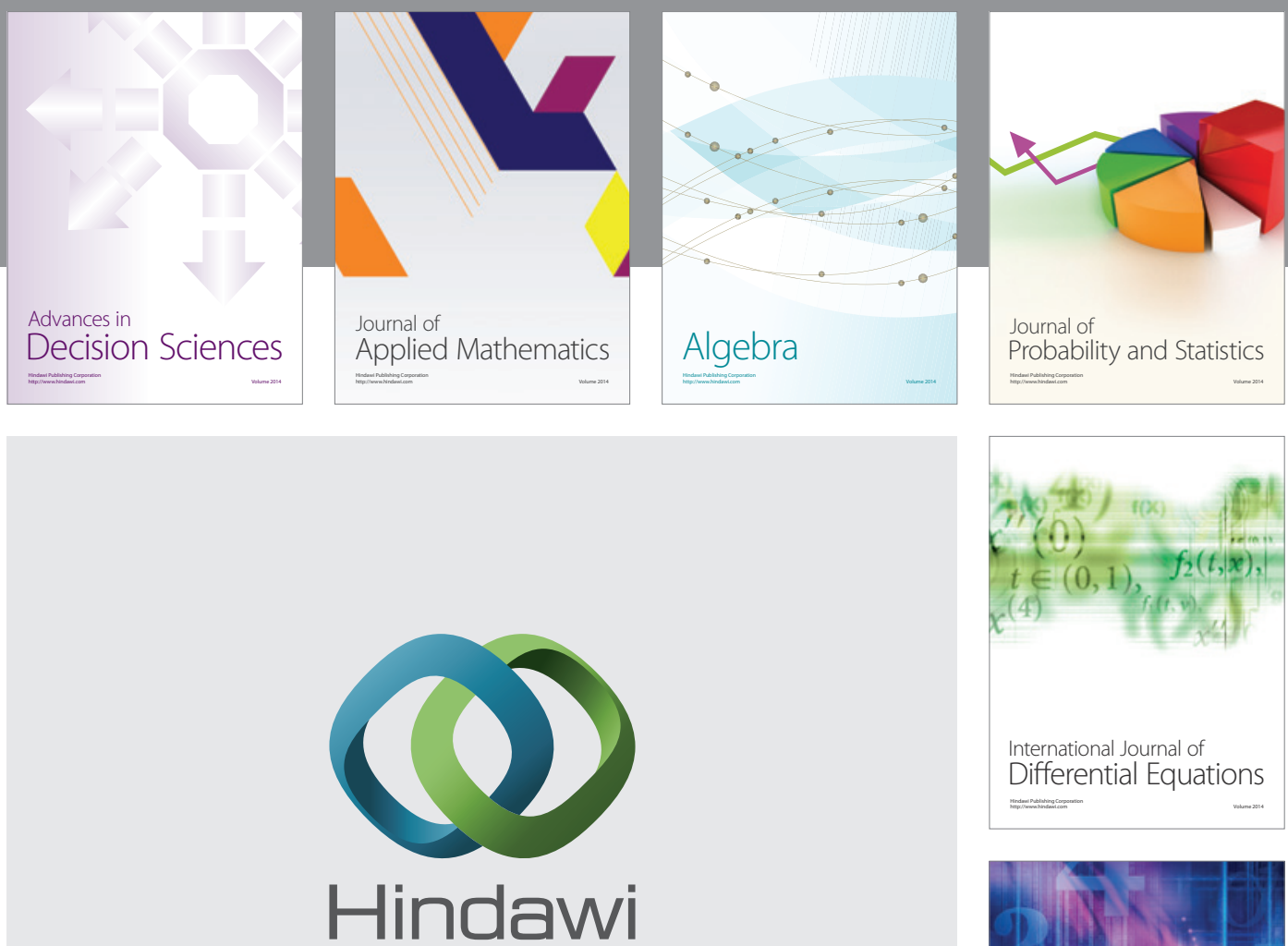

Submit your manuscripts at http://www.hindawi.com
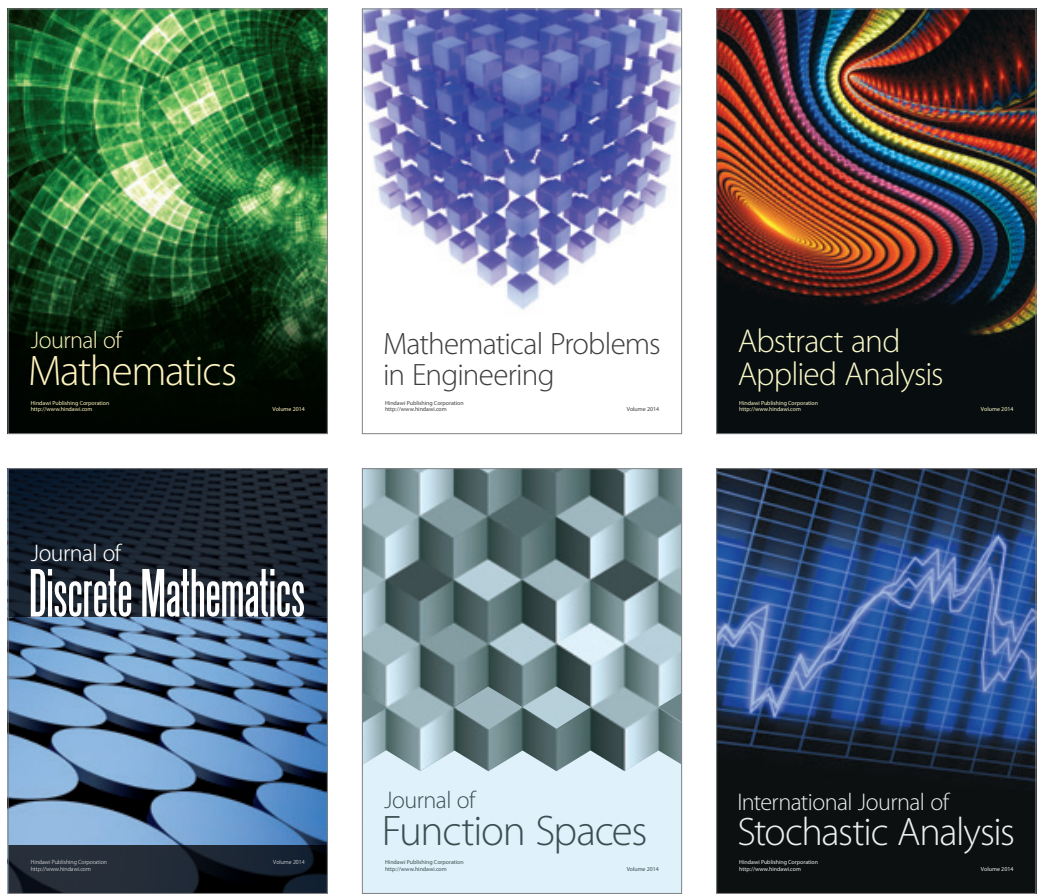

Journal of

Function Spaces

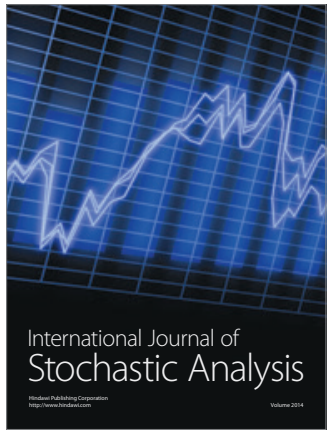

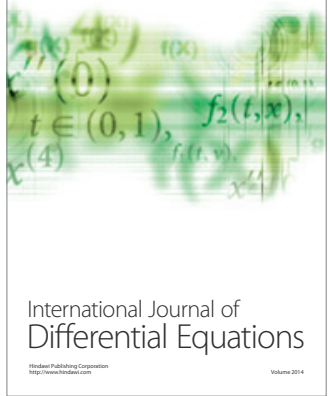
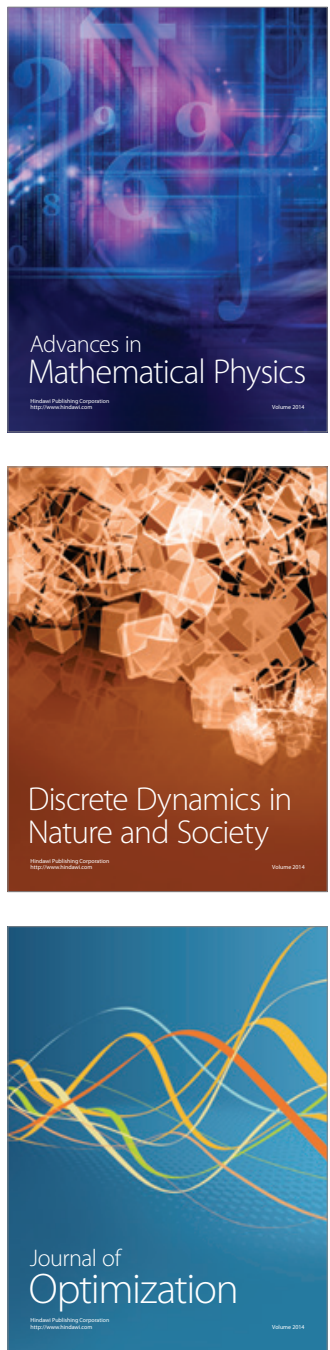